\title{
Highly active OMS-2 for catalytic ozone decomposition under humid conditions
}

\author{
Bo Peng ${ }^{1} \cdot$ Wenjing Bao $^{1} \cdot$ Linlin Wei $^{1} \cdot$ Runduo Zhang $^{1} \cdot$ Zhoujun Wang $^{1} \cdot$ Zhichun Wang $^{1} \cdot$ Ying Wei $^{1}$
}

Received: 10 September 2018 / Published online: 25 June 2019

(c) The Author(s) 2019

\begin{abstract}
Four kinds of cryptomelane-type octahedral molecular sieve (OMS)-2-X (the X represents the molar ratio of $\mathrm{KMnO}_{4} /$ $\mathrm{MnAc}_{2}$ ) were prepared as catalytic materials for ozone decomposition through a one-step hydrothermal reaction of $\mathrm{KMnO}_{4}$ and $\mathrm{MnAc}_{2}$, by changing their molar ratios. These samples were characterized by $\mathrm{N}_{2}$ adsorption-desorption, X-ray diffraction (XRD), transmission electron microscopy (TEM), scanning electron microscopy (SEM), temperature programmed reduction by $\mathrm{H}_{2}\left(\mathrm{H}_{2}\right.$-TPR) and X-ray photoelectron spectroscopy (XPS). Among them, the OMS-2-0.7 sample showed the best $\mathrm{O}_{3}$ conversion of $92 \%$ under high relative humidity (RH) of $90 \%$ and gas hourly space velocity of $585,000 \mathrm{~h}^{-1}$. This was accordingly thought as a possible way for purifying ozone-containing waste gases under high RH atmospheres. The efficiency of ozone decomposition of the prepared OMS-2-X sample was found to be related to specific surface area, particle size, surface oxygen vacancies, and $\mathrm{Mn}^{3+}$ cation amounts. The one-step hydrothermal synthesis was shown to be a simple method to prepare the considerably active OMS-2 solids for ozone decomposition.
\end{abstract}

Keywords Cryptomelane type $\cdot$ Manganese oxide $\cdot$ Ozone decomposition $\cdot$ Nanofiber $\cdot$ Oxygen vacancy

\section{Introduction}

Stratosphere ozone protects the human beings from ultraviolet light irradiation (Wang et al. 2015). However, the ozone in the troposphere can react with nitrogen oxides $\left(\mathrm{NO}_{x}\right)$ (Wang et al. 2011) and volatile organic compounds (VOCs), and the interaction among them is accelerated by light from the sun (Cooper et al. 2010; Afonso and Pires 2017), to form photochemical smog as a secondary air pollutant. Exposure to highly concentrated ozone for long periods can cause deleterious effects on human health involving blood pressure, lung function and airway inflammation, premature mortality,

Edited by Xiu-Qin Zhu and Xiu-Qiu Peng

Handling editor: Runduo Zhang

Runduo Zhang

zhangrd@mail.buct.edu.cn

Ying Wei

weiying@mail.buct.edu.cn

1 State Key Laboratory of Chemical Resource Engineering, Beijing Key Laboratory of Energy Environmental Catalysis, Beijing University of Chemical Technology, Beijing 100029, People's Republic of China and also decrease the harvest of staple crops (Hoffmann et al. 2012; Mohamed et al. 2018). What is more, tropospheric ozone as a greenhouse gas exacerbates global warming (Shindell et al. 2012). Nowadays, owing to its powerful oxidizing ability, ozone is widely applied in waste water treatment (Chen et al. 2017; Destaillats et al. 2008), sterilization and disinfection (Lin et al. 2016) and air purification (Mitchell et al. 2011; Yang et al. 2009), which leads to serious levels of ozone residues. Ozone can be released by much electrical equipment during discharge processes (Dhandapani and Oyama 1997) or oxygen irradiated by ultraviolet light (Zhu et al. 2017). Therefore, it is significant to study ozone decomposition for environment protection and human health.

Catalytic decomposition of ozone is used for purification of ozone-containing waste gases due to its efficient, convenient, safe, and economical advantages. The main active components of the catalysts are noble metals and transition metal oxides. The common noble metals for ozone decomposition are Pd (Yu et al. 2009), Ag (Zhang et al. 2009) and $\mathrm{Au}$ (Naydenov et al. 2008), while transition metal oxides are those of Ni (Stoyanova et al. 2006), Fe (Lian et al. 2015), Ce (Liu and Zhang 2017), Co (Ma et al. 2017) and Mn (Radhakrishnan and Oyama 2001). Dhandapani and Oyama (1997) have found that $\mathrm{MnO}_{2}$ exhibits the best activity for 
catalytic decomposition of ozone among the common metal oxides and concluded that the variety of valence of " $\mathrm{MnO}_{2}$ " might attribute to its excellent performance. For manganese oxides, different types of crystal structures correspond to diverse morphologies (Bai et al. 2015; Bing et al. 2017; Seo and Choi 2017; Ferraz et al. 2018). Octahedral molecular sieve (OMS)-2 (Cryptomelane-type manganese oxide) is one kind of $\mathrm{MnO}_{2}$. The structure of OMS-2 has an octahedral basic unit consisting of $2 \times 2$ shared edges to form a one-dimensional tunnel (Meng et al. 2014). The tunnel is $0.46 \mathrm{~nm} \times 0.46 \mathrm{~nm}$ (Saputra et al. 2013). In the octahedral structure of OMS-2, $\mathrm{Mn}^{2+}, \mathrm{Mn}^{3+}$, and $\mathrm{Mn}^{4+}$ valences are present (Genuino et al. 2012). The Mn(IV)/Mn(III) in OMS-2 boosts the oxidation process during catalytic removal of ethanol ( $\mathrm{Li}$ et al. 2010). OMS-2 is an ideal hydrophobic material (Luo et al. 2008) and may show good activity for ozone decomposition under relatively high humidity. Zhang's group (Liu and Zhang 2017; Jia et al. 2016a, b, 2017) have reported that oxygen vacancies are the main factor for the outstanding behavior of $\mathrm{MnO}_{2}$ in ozone decomposition under wet conditions due to different crystal structures and morphologies of $\mathrm{MnO}_{2}$. Zhu et al. (2017) also announced similar results by density functional theory (DFT) calculation for ozone $\left(\mathrm{O}_{3}\right)$ decomposition over OMS-2. The mechanism for catalytic decomposition of ozone mainly involves several redox steps, and oxygen vacancies are deemed as the active center (Zhu et al. 2017; Stoyanova et al. 2006; Lian et al. 2015; Liu and Zhang 2017; Jia et al. 2016a, 2017). However, synthesis of highly active OMS- 2 by varying the molar radio of $\mathrm{KMnO}_{4} /$ $\mathrm{MnAc}_{2}$ for ozone decomposition has not been reported in the literature. The role of surface characteristics of OMS-2 on its performance is so far not clear.

OMS-2-X catalysts were prepared with different molar ratios of $\mathrm{KMnO}_{4} / \mathrm{MnAc}_{2}$ and characterized by a variety of means including $\mathrm{N}_{2}$ adsorption-desorption, XRD, TEM, SEM, $\mathrm{H}_{2}$-TPR and XPS. These as-prepared OMS-2-X samples were used as catalysts under relatively high humidity for ozone decomposition.

\section{Materials and methods}

\subsection{Sample preparation method}

The catalysts were prepared with different molar ratios of potassium permanganate $\left(\mathrm{KMnO}_{4}\right)$ to $\mathrm{MnAc}_{2} \cdot 4 \mathrm{H}_{2} \mathrm{O}$ by a hydrothermal method, which was a similar process to that reported by Wang et al. (2015). OMS-2-0.9 was prepared with a molar ratio of 0.9 as follows: $14.9 \mathrm{mmol}$ of $\mathrm{MnAc}_{2} \bullet 4 \mathrm{H}_{2} \mathrm{O}$ was mixed in $20 \mathrm{~mL}$ deionized water by stirring. Thereafter, an acidic environment was achieved by adding $2.0 \mathrm{ml}$ acetic acid. Next, potassium permanganate solution $(60 \mathrm{ml}$ deionized water was used to dissolve
$13.4 \mathrm{mmol} \mathrm{KMnO}_{4}$ ) was added dropwise into the previous solution. Finally, the resulting mixture was transferred into a Teflon kettle at an oven $100{ }^{\circ} \mathrm{C}$ for $24 \mathrm{~h}$. The obtained material was filtered first and then washed several times with deionized water until the filter liquor was $\mathrm{pH}=7$. The residue was put into a $100{ }^{\circ} \mathrm{C}$ oven to dry for $8 \mathrm{~h}$. This method was conducted for the OMS-2-0.9 sample. The other kinds of OMS-2-X materials were called OMS-2-0.7 $\left(\mathrm{KMnO}_{4} /\right.$ $\left.\mathrm{MnAc}_{2}=0.7\right)$, OMS-2-0.5 $\left(\mathrm{KMnO}_{4} / \mathrm{MnAc}_{2}=0.5\right)$ and OMS-2-0.3 $\left(\mathrm{KMnO}_{4} / \mathrm{MnAc}_{2}=0.3\right)$, where the $\mathrm{X}$ represents the molar ratio of $\mathrm{KMnO}_{4} / \mathrm{MnAc}_{2}$.

\subsection{Catalyst characterization}

OMS-2-X was investigated using X-ray diffractometry (XRD) to confirm its crystalline structure using $\mathrm{Cu} \mathrm{K \alpha}$ radiation at $40 \mathrm{kV}(\lambda=0.15406 \mathrm{~nm})$. The corresponding data were obtained over the range of $2 \theta$ from $5^{\circ}$ to $80^{\circ}$ and a step value of $0.02^{\circ}$.

XPS was performed on a Thermofisher ESCALAB 250 system. The binding energies (BE) of the $\mathrm{C} 1 s$ were at $285.0 \mathrm{eV}$ to calibrate the measured results.

The morphologies of the four kinds of OMS-2 catalysts were observed by field emission scanning electron microscopy (FESEM) with a Hitachi SU8000 at $10.0 \mathrm{kV}$. The TEM images were obtained in a JEOL 2100 electron microscope at $200 \mathrm{kV}$. The samples dispersed in ethanol were dropped onto a copper grid.

$\mathrm{N}_{2}$ adsorption/desorption isotherms were used to investigate the specific surface areas and pore structures including average pore sizes, pore size distributions, and total pore volumes. A Micromeritics ASAP 2460 analyzer was operated to analyze surface areas by using the Brunauer-Emmett-Teller (BET) method. The distribution of sample pore sizes was determined by the Barrett-Joyner-Halenda (BJH) method.

$\mathrm{H}_{2}$-TPR was undertaken on an instrument made in-house. The gas contains $5.58 \%$ of $\mathrm{H}_{2}$ balanced by $\mathrm{Ar}$ under atmospheric pressure. For each test, $100 \mathrm{mg}$ samples were loaded with a reduction temperature between 150 and $500{ }^{\circ} \mathrm{C}$. A thermo-conductivity detector (TCD) was used to check the $\mathrm{H}_{2}$ consumption amount caused by reduction.

\subsection{Activity evaluation}

Ozone decomposition was conducted in a quartz reactor (diameter $5 \mathrm{~mm}$ ) at $25{ }^{\circ} \mathrm{C}$ and at a space velocity of $585,000 \mathrm{~h}^{-1}$. Gas flows were $\mathrm{O}_{2}$ and $\mathrm{N}_{2}$ with $50,1000 \mathrm{~mL} /$ min, respectively. An ozone generator (Jiangxi Nicey Technology Co., Ltd., China) was used to generate ozone which was $500 \mathrm{ppm}$ in the inlet. An ozone monitor made by $2 \mathrm{~B}$ Technologies (model 202) detected inlet or outlet ozone concentrations. A bubbler was kept at a constant temperature $\left(32{ }^{\circ} \mathrm{C}\right)$ to maintain the relative humidity $(\mathrm{RH}=90 \%)$, which 
is measured by means of a humidity indicator (CENTER 313, Taiwan Center Electronics CO., Ltd., China). The following was ozone conversion formula (1):

Ozone conversion $=\frac{C_{\text {in }}-C_{\text {out }}}{C_{\text {in }}} \times 100 \%$

\section{Results and discussion}

\subsection{XRD results}

Materials prepared by the different ratios of $\mathrm{KMnO}_{4} / \mathrm{MnAc}_{2}$ were well crystallized along with the octahedral molecular sieve which exhibited the characteristics of JCPDS 29-1020 (see Fig. 1). OMS-2-X showed the main peaks at $12.7^{\circ}, 18.0^{\circ}$, $28.7^{\circ}, 37.6^{\circ}, 42.0^{\circ}, 49.9^{\circ}$, and $60.2^{\circ}$. The variations in peaks of the synthesized materials exhibited some difference in crystal size. Scherrer's formula was used to calculate the size of OMS-2-X crystals $(d=0.89 \lambda / \beta \cos \theta)$. Among the investigated samples, OMS-2-0.7 had the smallest crystal size of $7.7 \mathrm{~nm}$ and OMS-2-0.3 presented the largest size of $9.9 \mathrm{~nm}$. In addition, OMS-2-0.5 was $8.2 \mathrm{~nm}$ and OMS-2-0.9 was $9.3 \mathrm{~nm}$.

\subsection{TEM and SEM results for OMS-2-X}

The morphologies observed using SEM and TEM are depicted in Fig. 2. The samples showed typical nanorod morphology. OMS-2-0.7 showed nanoscaled images with the smallest diameter of about $6.4 \mathrm{~nm}$ and lengths of $31-93 \mathrm{~nm}$. Moreover, OMS-2-0.3 had the largest diameter of about $9.4 \mathrm{~nm}$ and lengths of 50-125 nm. OMS-2-0.9 and OMS-2-0.5 presented the medium diameter of $9.1 \mathrm{~nm}$ and $7.1 \mathrm{~nm}$, respectively.

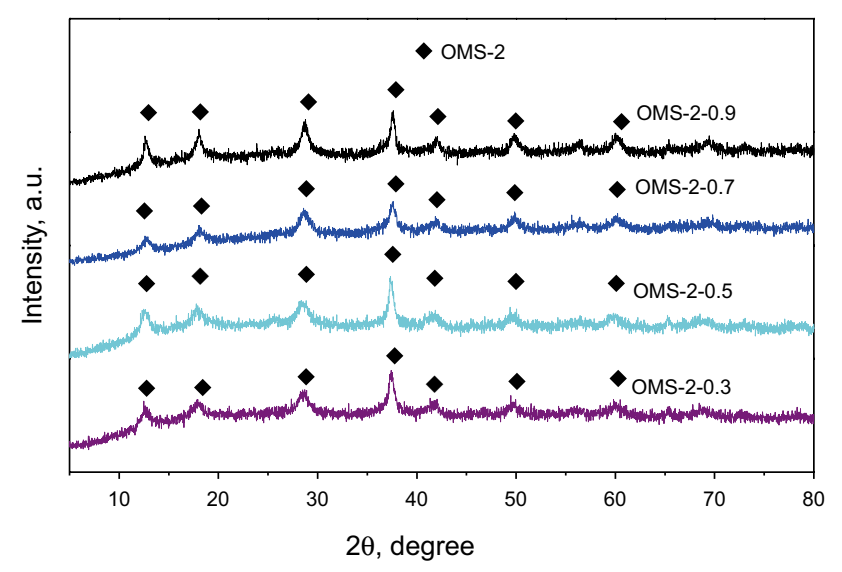

Fig. 1 XRD patterns of the catalysts prepared by the different ratios of $\mathrm{KMnO}_{4} / \mathrm{MnAc}_{2}$

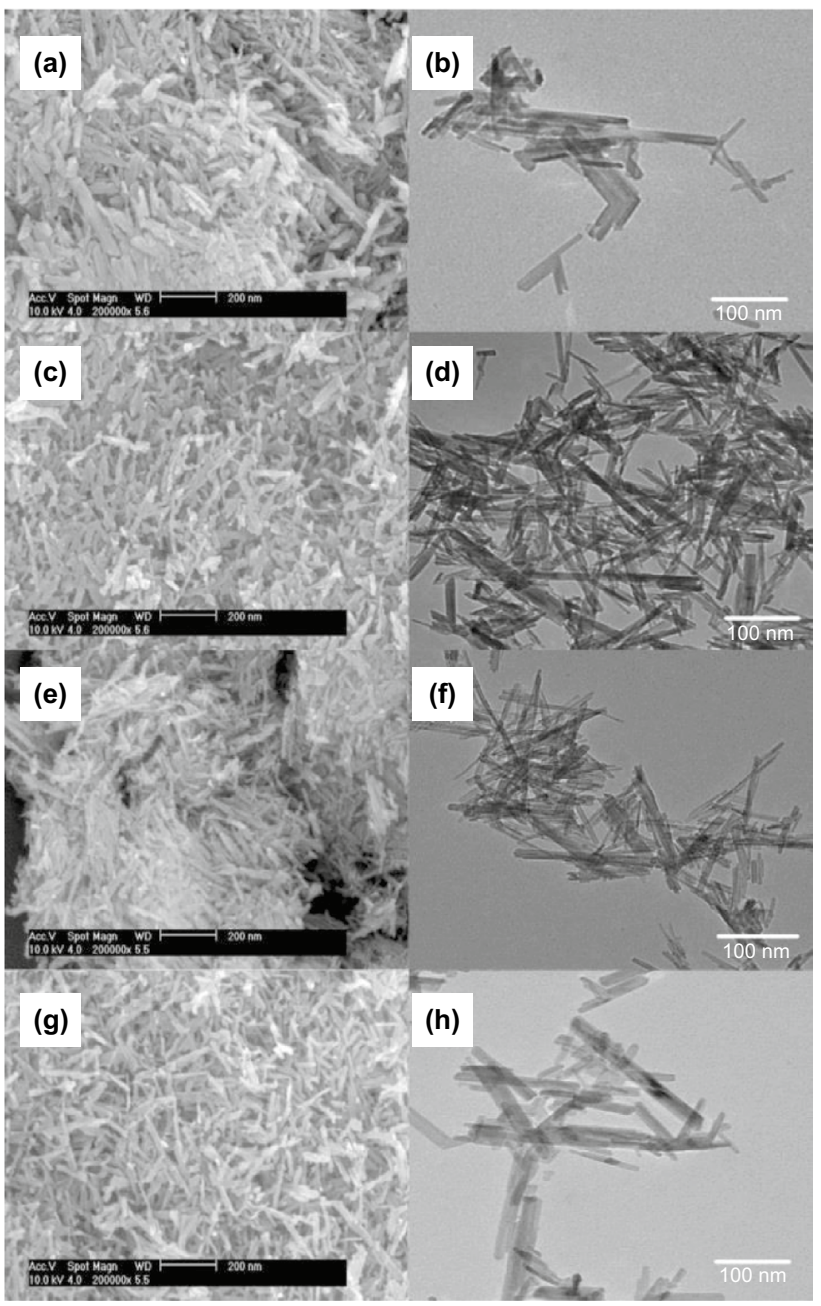

Fig. 2 SEM (left) and TEM (right) photographs for the OMS-2-0.3 (a, b), OMS-2-0.5 (c, d), OMS-2-0.7 (e, f), OMS-2-0.9 (g, h) catalysts

\subsection{Effect of surface areas of OMS-2-X}

The $\mathrm{N}_{2}$ adsorption/desorption isotherms are displayed in Fig. 3. The isotherms of OMS-2-0.9, OMS-2-0.7 and OMS2-0.5 displayed the typical $\mathrm{H} 3$ hysteresis loop which belongs to the type II isotherm by the IUPAC classification. These results are usually associated with the adsorption on pores secondarily formed by construction of primary particles (Sun et al. 2013). These were similar to the previous results of OMS-2 (Ma et al. 2017). The OMS-2-0.3 showed the type I isotherm pattern, an H4-type hysteresis loop from adsorption by slit-like holes created by layered structures. The OMS2-0.7 showed higher slopes than those of the other samples at low $P / P_{\mathrm{o}}$ which indicated a relatively higher surface area. Compared with OMS-2-0.3 and OMS-2-0.9 $\left(0.091 \mathrm{~cm}^{3} / \mathrm{g}\right.$, $0.423 \mathrm{~cm}^{3} / \mathrm{g}$ ), OMS-2-0.7 and OMS-2-0.5 showed relatively larger pore volumes $\left(0.435 \mathrm{~cm}^{3} / \mathrm{g}, 0.681 \mathrm{~cm}^{3} / \mathrm{g}\right)$. OMS-2- 0.5 had the largest average pore diameter $(17.3 \mathrm{~nm})$ with respect 


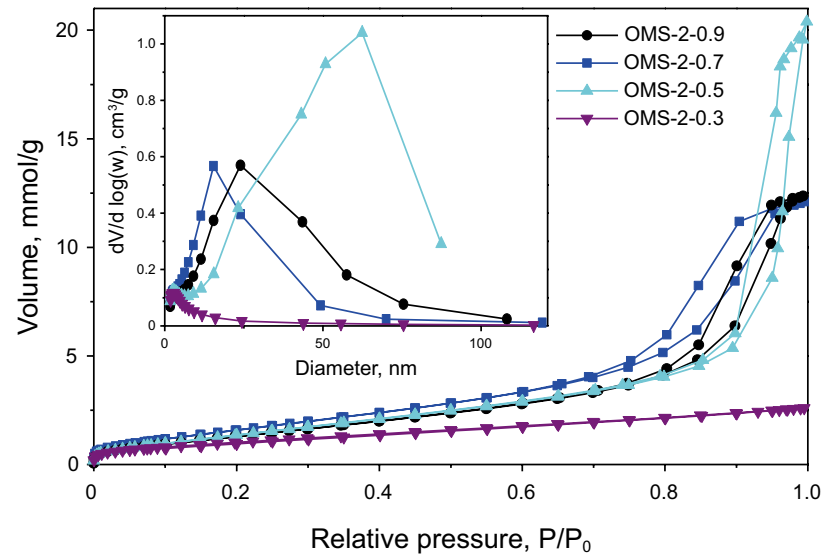

Fig. 3 Nitrogen adsorption/desorption isotherms and pore diameter distribution of the OMS-2-X catalysts

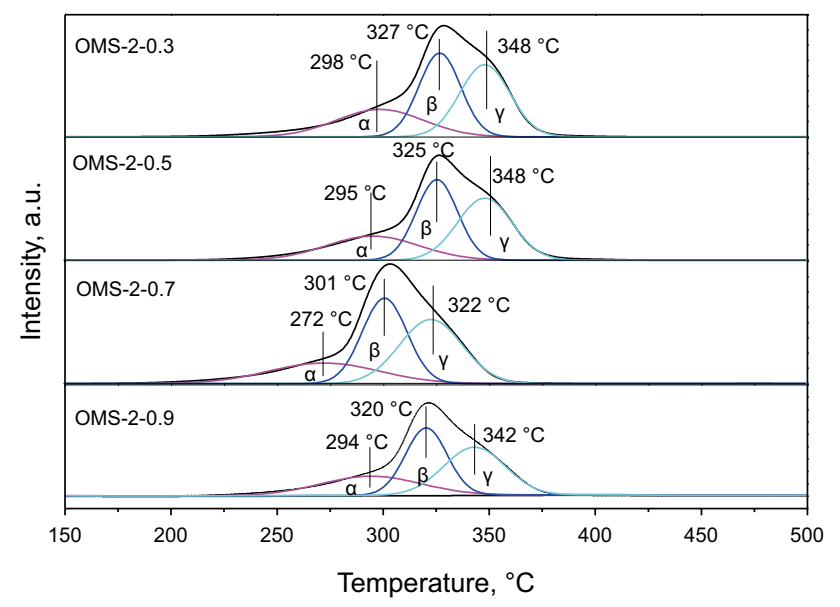

Fig. $4 \mathrm{H}_{2}$-TPR results of the catalysts

to OMS-2-0.3 (4.1 nm), OMS-2-0.7 (10.9 nm), OMS-2-0.9 $(9.1 \mathrm{~nm})$, which may favor ozone entering its tunnels and promoting ozone decomposition under relatively high space velocity and humidity. The specific surface area for four samples was OMS-2-0.3 (91 m²/g), OMS-2-0.5 $\left(135 \mathrm{~m}^{2} / \mathrm{g}\right)$, OMS-2-0.7 $\left(154 \mathrm{~m}^{2} / \mathrm{g}\right)$, and OMS-2-0.9 $\left(134 \mathrm{~m}^{2} / \mathrm{g}\right)$. The
OMS-2-0.7 had the highest surface area of the OMS-2-Xs, probably being the main reason for its better performance.

\subsection{Redox behavior of the samples}

Temperature-programmed reduction profiles are presented in Fig. 4 to reveal the redox properties of the four OMS-2 materials. These show three overlapped reduction peaks in accordance with a three-step reduction process. These three overlapped peaks were labeled as $\alpha, \beta, \gamma$, respectively. The reduction characteristics of the cryptomelane structure materials had been studied in early work (Wang et al. 2015; Sun et al. 2013). Firstly, the $\alpha$ peak was the temperature reduction process by which the $\mathrm{MnO}_{2}$ was reduced to $\mathrm{Mn}_{2} \mathrm{O}_{3}$. Secondly, the transformation from $\mathrm{Mn}_{2} \mathrm{O}_{3}$ to $\mathrm{Mn}_{3} \mathrm{O}_{4}$ was associated with the $\beta$ peak. Lastly, the materials were further reduced to $\mathrm{MnO}$ and this showed as the $\gamma$ peak. As for OMS-2-0.7, the $\alpha, \beta$ and $\gamma$ peaks occur at 272, 301, and $322^{\circ} \mathrm{C}$, which are lower than the corresponding peaks of OMS-2-0.3 (298, 327, $\left.348{ }^{\circ} \mathrm{C}\right)$, OMS-2-0.5 (293, 325, $\left.347^{\circ} \mathrm{C}\right)$, and OMS-2-0.9 $\left(294,320,342^{\circ} \mathrm{C}\right)$, implying that OMS-2-0.7 presented the best reducibility. What is more, the total $\mathrm{H}_{2}$ consumption amount of the $\alpha$ peak followed the sequence of OMS-2-0.7 $(9.06 \mathrm{mmol} / \mathrm{g})<$ OMS-2-0.5 $(9.30 \mathrm{mmol} / \mathrm{g})<$ OMS-2-0.9 $(9.56 \mathrm{mmol} / \mathrm{g})<$ OMS-2- 0.3 $(9.60 \mathrm{mmol} / \mathrm{g})$. The $\alpha$ and $\beta$ peaks had the same sequence of $\mathrm{H}_{2}$ consumption amount which is shown in Table 1. For the reduction from $\mathrm{MnO}_{2}$ to $\mathrm{MnO}$, each $\mathrm{H}_{2}$ consumption amount was smaller than the theoretical one, which implied that a certain amount of $\mathrm{Mn}^{3+}$ existed in all the four OMS-2 samples. We could deduce that the molar ratio of $\mathrm{O}$ and $\mathrm{Mn}$ was 3.50 on the OMS-2-0.7 structure which was the lowest value. However, the OMS-2-0.3 showed the highest ratio of 3.61 which was closed to the related value of OMS-2-0.9 (3.60). The other was 3.55 (OMS-2-0.5). Among them, the $\mathrm{Mn}^{3+}$ content decreased inversely to the molar ratio of $\mathrm{O}$ and $\mathrm{Mn}$.

\subsection{Chemical states of surface elements}

The XPS in Fig. 5 showed that the chemical states of Mn and $\mathrm{O}$ in the four samples were $\mathrm{O} 1 s, \mathrm{Mn} 2 p_{3 / 2}$ and $\mathrm{Mn} 3 s$ spectra. In Fig. 5a, there were two peaks divided on Mn $2 p_{3 / 2}$

Table $1 \mathrm{H}_{2}$-TPR results of the catalysts prepared with different ratios of $\mathrm{MnO}_{4}{ }^{-} / \mathrm{Mn}^{2+}$

\begin{tabular}{|c|c|c|c|c|c|c|c|}
\hline \multirow[t]{2}{*}{ Sample } & \multicolumn{2}{|l|}{ Peak $\alpha$} & \multicolumn{2}{|l|}{ Peak $\beta$} & \multicolumn{2}{|l|}{ Peak $\gamma$} & \multirow{2}{*}{$\begin{array}{l}\text { Total } \mathrm{H}_{2} \text { consumption, } \\
\mathrm{mmol} / \mathrm{g}\end{array}$} \\
\hline & $\begin{array}{l}\text { Peak posi- } \\
\text { tion, }{ }^{\circ} \mathrm{C}\end{array}$ & $\begin{array}{l}\mathrm{H}_{2} \text { consumption, } \\
\mathrm{mmol} / \mathrm{g}\end{array}$ & $\begin{array}{l}\text { Peak posi- } \\
\text { tion, }{ }^{\circ} \mathrm{C}\end{array}$ & $\begin{array}{l}\mathrm{H}_{2} \text { consumption, } \\
\mathrm{mmol} / \mathrm{g}\end{array}$ & $\begin{array}{l}\text { Peak posi- } \\
\text { tion, }{ }^{\circ} \mathrm{C}\end{array}$ & $\begin{array}{l}\mathrm{H}_{2} \text { consumption, } \\
\mathrm{mmol} / \mathrm{g}\end{array}$ & \\
\hline OMS-2-0.3 & 298 & 2.41 & 327 & 3.53 & 348 & 3.66 & 9.60 \\
\hline OMS-2-0.5 & 293 & 2.25 & 325 & 3.41 & 347 & 3.64 & 9.30 \\
\hline OMS-2-0.7 & 272 & 1.96 & 301 & 3.38 & 322 & 3.72 & 9.06 \\
\hline OMS-2-0.9 & 294 & 2.39 & 320 & 3.51 & 342 & 3.67 & 9.56 \\
\hline
\end{tabular}



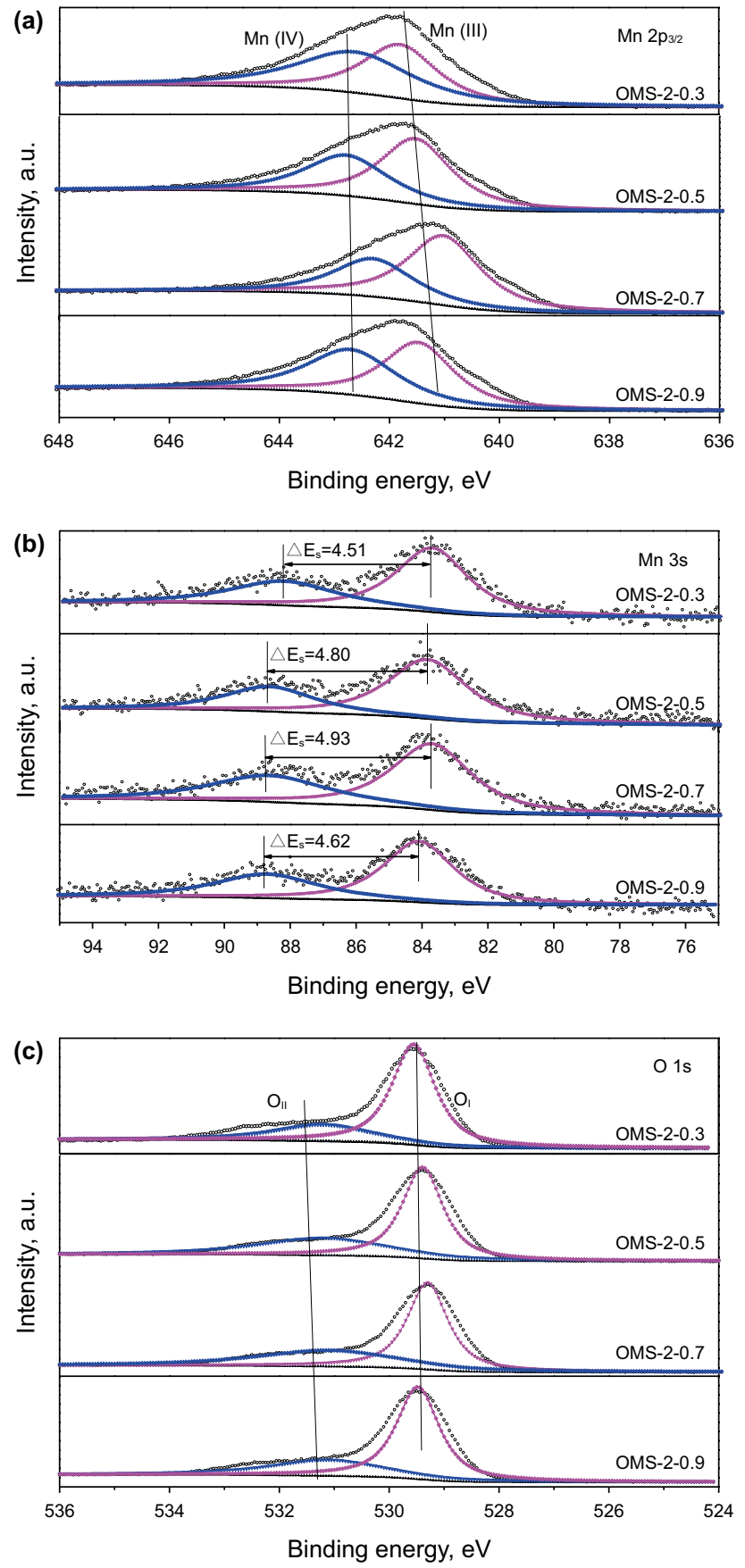

Fig. 5 Mn $2 p(\mathbf{a}), \operatorname{Mn} 3 s$ (b) and O $1 s$ (c) XPS of the OMS-2-X catalysts

which was the surface $\mathrm{Mn}^{3+}(641.5 \mathrm{eV})$ species and $\mathrm{Mn}^{4+}$ $(642.7 \mathrm{eV})$ species.

The quantitative analysis of different molar ratios of surface $\mathrm{Mn}^{3+} / \mathrm{Mn}^{4+}$ is shown in Table 2. The OMS-2-0.7 sample showed a molar ratio of 1.70 which was the highest value of surface $\mathrm{Mn}^{3+} / \mathrm{Mn}^{4+}$ among the four samples. OMS-2-0.3 had an $\mathrm{Mn}^{3+} / \mathrm{Mn}^{4+}$ molar ratio equal to 0.86 , while material OMS-2-0.5 possessed a ratio of 1.38 and OMS-2-0.9 only had a ratio of 1.08 . These were consistent with the $\mathrm{H}_{2}$-TPR result of the $\mathrm{Mn}^{3+}$ content. It is known that when $\mathrm{Mn}^{3+}$ is contained in the framework, oxygen vacancies would be formed on manganese dioxide. Maintaining electrostatic balance was the reason which concluded the following process (2) (Hou et al. 2016; Jia et al. 2016a, b). According to this process, we calculate that OMS-2-0.7 had a surface oxygen vacancy content of $19 \%$. OMS-2-0.5 had a vacancy content of $12.5 \%$, which is lower than that of OMS-2-0.7. In contrast, there were few surface oxygen vacancies for OMS2-0.9 (1\%) and OMS-2-0.3 (0.5\%). The oxygen vacancy site was represented by $V_{\mathrm{o}}$.

$$
\begin{gathered}
4 \mathrm{Mn}^{4+}+\mathrm{O}^{2-} \rightarrow 4 \mathrm{Mn}^{4+} \\
+\frac{2 \mathrm{e}^{-}}{V_{\mathrm{o}}}+\frac{1}{2} \mathrm{O}_{2} \rightarrow 2 \mathrm{Mn}^{4+} \\
+2 \mathrm{Mn}^{3+}+V_{\mathrm{o}}+\frac{1}{2} \mathrm{O}_{2} \\
\text { AOS }=8.956-1.126 \Delta E_{\mathrm{s}}
\end{gathered}
$$

The average oxidation state (AOS) results were obtained from formula (3), and the $\Delta E_{\mathrm{s}}$ was doublet binding-energy peaks for Mn $3 s$ (Fig. 5b) (Hou et al. 2016). The AOS of OMS-2-0.7 was 3.40 which is much lower than OMS-2-0.3 (3.88). The material OMS-2-0.5 was the middle of the above results (3.55) and so was OMS-2-0.9 (3.75). These suggested that $\mathrm{Mn}^{3+}$ in the lattice of OMS-2-0.7 was the highest oxidation state. This observation was in agreement with that obtained from $\mathrm{H}_{2}$-TPR.

In Fig. 5c, the $\mathrm{O} 1 s$ spectra showed two surface oxygen species. The binding-energy (BE) peaks of 529.4-529.9 eV were assigned to the lattice oxygen $\left(\mathrm{O}_{\mathrm{I}}\right)$, which was $\mathrm{O}^{2-}$, while the surface oxygen species were shown as $\mathrm{O}_{2}{ }^{-}, \mathrm{O}^{-}$, $\mathrm{HO}^{-}$groups and allocated to the higher $\mathrm{BE}(531.0-531.2 \mathrm{eV})$ peaks (Jia et al. 2016a, b). The molar ratio of $\mathrm{O}_{\mathrm{II}} / \mathrm{O}_{\mathrm{I}}$ is in keeping with the ratio of $\mathrm{Mn}^{3+} / \mathrm{Mn}^{4+}$ for these materials (see Table 2). An oxidative material was formed by the process of oxygen molecules adsorbing at the oxygen vacancies. This confirmed the order of the density of oxygen vacancies.

\subsection{Catalytic activity}

All OMS-2-X samples displayed good activity for ozone decomposition under dry conditions and all of them reached 100\% (see Fig. 6). However, Fig. 7 shows that the catalytic performance of OMS-2 materials for ozone removal when the relative humidity (RH) was $90 \%$. OMS-2-0.7 kept an activity of $92 \%$ after $0.5 \mathrm{~h}$ and maintained this activity for $7 \mathrm{~h}$ without further decline. But the activity of OMS-2-0.5 dropped to $80 \%$ of the initial value after $1.5 \mathrm{~h}$. The ozone conversions of OMS-2-0.9 and OMS-2-0.3 were diminished to $72 \%$ and $68 \%$, respectively, of the initial value after $2.5 \mathrm{~h}$. 
Table 2 XPS results for the OMS-2-X catalysts

\begin{tabular}{|c|c|c|c|c|c|c|c|c|}
\hline \multirow[t]{2}{*}{ Sample } & \multicolumn{3}{|l|}{$\operatorname{Mn} 2 p_{3 / 2}$} & \multirow{2}{*}{$\begin{array}{l}\text { Mn } 3 s \\
\text { AOS of Mn }\end{array}$} & \multicolumn{3}{|l|}{$\mathrm{O} 1 s$} & \multirow[t]{2}{*}{$\mathrm{K} / \mathrm{Mn}$} \\
\hline & $\mathrm{Mn}(\mathrm{III}), \%$ & $\mathrm{Mn}(\mathrm{IV}), \%$ & $\mathrm{Mn}(\mathrm{III}) / \mathrm{Mn}(\mathrm{IV})$ & & $\mathrm{O}_{\mathrm{I}}, \%$ & $\mathrm{O}_{\mathrm{II}}, \%$ & $\mathrm{O}_{\mathrm{II}} / \mathrm{O}_{\mathrm{I}}$ & \\
\hline OMS-2-0.3 & 46.1 & 53.9 & 0.86 & 3.88 & 72.7 & 27.3 & 0.37 & 0.11 \\
\hline OMS-2-0.5 & 58.0 & 42.0 & 1.38 & 3.55 & 62.2 & 37.8 & 0.61 & 0.20 \\
\hline OMS-2-0.7 & 63.0 & 37.0 & 1.70 & 3.40 & 60.6 & 39.4 & 0.65 & 0.22 \\
\hline OMS-2-0.9 & 51.9 & 48.1 & 1.08 & 3.75 & 68.2 & 31.8 & 0.46 & 0.23 \\
\hline
\end{tabular}

$\mathrm{O}_{\mathrm{I}}$, lattice oxygen $\left(\mathrm{O}^{2-}\right)$; $\mathrm{O}_{\mathrm{II}}$, surface adsorbed oxygen $\left(\mathrm{O}_{2}^{-}\right.$or $\left.\mathrm{O}^{-}\right), \mathrm{HO}^{-}$groups and oxygen vacancies

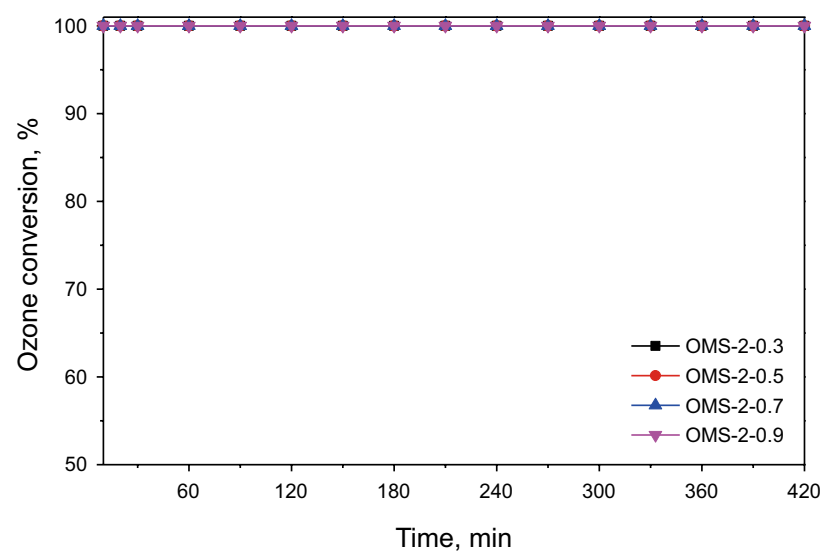

Fig. 6 Conversion of ozone on the OMS-2-X catalysts at $25^{\circ} \mathrm{C}$ and a space velocity of $585,000 \mathrm{~h}^{-1}$

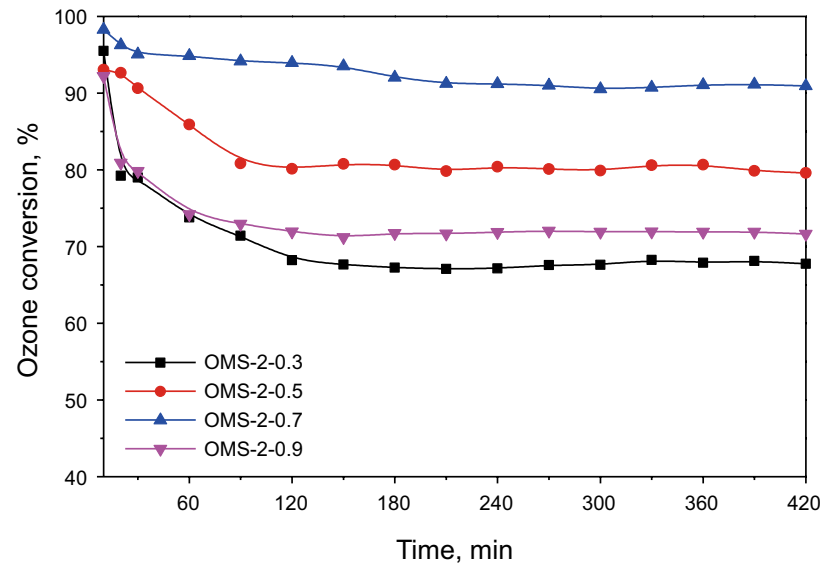

Fig. 7 Conversion of ozone on the OMS-2-X catalysts at $25{ }^{\circ} \mathrm{C}$, a space velocity of $585,000 \mathrm{~h}^{-1}$ and relative humidity of $90 \%$

OMS-2-0.7 had the highest activity and kept stable longer than the other materials.

Smaller particles are beneficial for the formation of more defects. The crystal size determined by XRD indicated that the activity of ozone decomposition increased along with the smaller catalyst size. Moreover, SEM and TEM confirmed the smaller size is associated with better activity which is in agreement with the previous conclusions (Ma et al. 2017; Jia et al. 2016a, b). The surface area of the most active OMS-2$0.7\left(154 \mathrm{~m}^{2} / \mathrm{g}\right)$ was the highest in the four OMS-2 materials. The worst activity was achieved over OMS-2-0.3 $\left(91 \mathrm{~m}^{2} / \mathrm{g}\right)$ which had the lowest surface area. A large surface area could expose more active sites for the adsorption of ozone and essentially promote ozone depletion on OMS-2-0.7. However, OMS-2-0.5 $\left(135 \mathrm{~m}^{2} / \mathrm{g}\right)$ and OMS-2-0.9 $\left(134 \mathrm{~m}^{2} / \mathrm{g}\right)$ displayed similar surface areas along with the distinct activity. Therefore, the specific surface area was likely not the key issue of discrepancy in the activity of the samples (Wang et al. 2015; Ma et al. 2017).

The OMS-2 framework can easily form oxygen vacancies by some of oxygen atoms escaping from the framework while maintaining its crystal structure (Luo et al. 2008). The reaction mechanism reported by Jia was that the oxygen vacancies were the reason for the improvement of the ozone decomposition (Jia et al. 2016a, b). Surface oxygen vacancy densities were effective for evaluation of the amount of oxygen species adsorbed on the sample surface. From XPS results, the OMS-2-0.7 showed the most adsorbed surface oxygen species, which was in agreement with its the highest catalytic activity, as illustrated in Fig. 5 for O $1 s$ XPS. The content of oxygen vacancies was calculated by Eq. (2) and the activity of ozone removal was indeed enhanced as the oxygen vacancy proportion increased. The oxygen vacancy content of OMS-2-0.7 and OMS-2-0.5 was much more than those for OMS-2-0.9 and OMS-2-0.3, which coincided with effective ozone removal. Hence, the activity for ozone elimination was strongly related to the surface oxygen vacancies. The mechanism of ozone decomposition involved many redox steps ( $\mathrm{Li}$ et al. 1998). The $\mathrm{H}_{2}$-TPR investigation demonstrated that the OMS-2-0.7 had the lowest reduction temperature and the best reducibility which was beneficial for ozone decomposition. $\mathrm{H}_{2}$ consumption could display the oxygen amount of each material and its ability to form vacancies. Three reducing peaks for OMS2-X showed the different $\mathrm{H}_{2}$ consumption amounts following almost the same order of activity of ozone decomposition (see Table 1). The more $\mathrm{H}_{2}$ that is consumed, the better the 


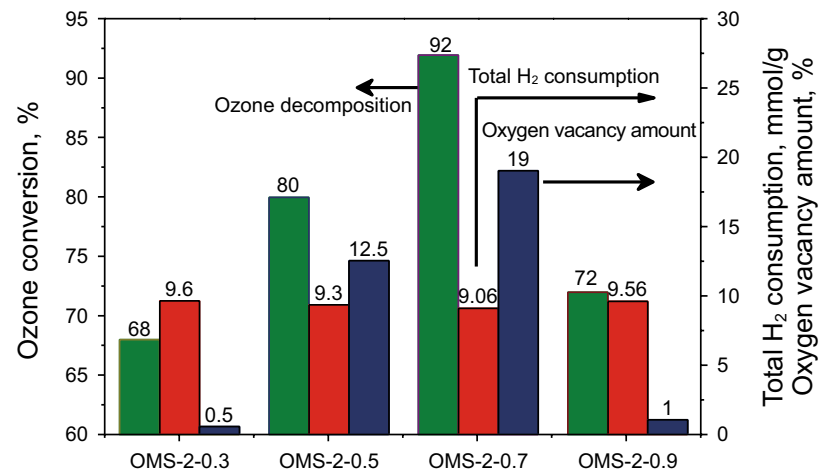

Fig. 8 The relation of stable ozone decomposition (green), total $\mathrm{H}_{2}$ consumption (red) and oxygen vacancy (blue) on OMS-2-X

ozone decomposition efficiency achieved. The total $\mathrm{H}_{2}$ consumption and oxygen vacancy amount had a good relationship with ozone decomposition as illustrated in Fig. 8. A lower total $\mathrm{H}_{2}$ consumption and a higher oxygen vacancy amount would enhance the ozone decomposition. Wang and Liu et al. found higher surface $\mathrm{Mn}^{3+}$ levels would promote ozone decomposition (Ma et al. 2017; Liu et al. 2014). Both XPS and $\mathrm{H}_{2}$-TPR showed that the $\mathrm{Mn}^{3+}$ amount in OMS2 -X plays a key role in ozone catalytic removal. Hence, the higher amount of $\mathrm{Mn}^{3+}$ cations promoted the effective removal ozone by OMS-2-0.7.

\section{Conclusions}

Four kinds of OMS-2 with different molar ratios were prepared by chemical thermal synthesis involving both potassium permanganate and $\mathrm{MnAc}_{2}$. OMS-2-X showed distinct behaviors during ozone decomposition. OMS-2-0.7 synthesized with a molar ratio of 0.7 exhibited an excellent activity for ozone decomposition. XRD, SEM and TEM characterizations suggested that smaller particles and larger surface area were beneficial for ozone removal. Most importantly, the content of $\mathrm{Mn}^{3+}$ ions and surface oxygen vacancies were the key for effectively decomposing ozone under high relative humidity conditions.

Acknowledgements The authors appreciate the financial support from the National Natural Science Foundation of China (No. U1862102) and the Fundamental Research Funds for the Central Universities (XK1802-1, JD1819).

Open Access This article is distributed under the terms of the Creative Commons Attribution 4.0 International License (http://creativeco mmons.org/licenses/by/4.0/), which permits unrestricted use, distribution, and reproduction in any medium, provided you give appropriate credit to the original author(s) and the source, provide a link to the Creative Commons license, and indicate if changes were made.

\section{References}

Afonso NF, Pires J. Characterization of surface ozone behavior at different regimes. Appl Sci. 2017;7(9):944. https://doi.org/10.3390/ app7090944.

Bai B, Li J, Hao J. 1D-MnO 2 , 2D- $\mathrm{MnO}_{2}$ and 3D- $\mathrm{MnO}_{2}$ for low-temperature oxidation of ethanol. Appl Catal B Environ. 2015;164:24150. https://doi.org/10.1016/j.apcatb.2014.08.044.

Bing Y, Zhang L, Mu S, et al. Facile synthesis of $\alpha-\mathrm{MnO}_{2}$ with a 3D staghorn coral-like micro-structure assembled by nano-rods and its application in electrochemical supercapacitors. Appl Sci. 2017;7(5):511. https://doi.org/10.3390/app7050511.

Chen Y, Chen C, Yoza BA, et al. Efficient ozonation of reverse osmosis concentrates from petroleum refinery wastewater using composite metal oxide-loaded alumina. Pet Sci. 2017;14:605-15. https://doi. org/10.1007/s12182-017-0178-x.

Cooper OR, Parrish DD, Stohl A, et al. Increasing springtime ozone mixing ratios in the free troposphere over western North America. Nature. 2010;463(7279):344-8. https://doi.org/10.1038/natur e08708.

Destaillats H, Maddalena RL, Singer BC, et al. Indoor pollutants emitted by office equipment: a review of reported data and information needs. Atmos Environ. 2008;42(7):1371-88. https://doi. org/10.1016/j.atmosenv.2007.10.080.

Dhandapani B, Oyama ST. Gas phase ozone decomposition catalysts. Appl Catal B Environ. 1997;11(2):129-66. https://doi. org/10.1016/S0926-3373(96)00044-6.

Ferraz CP, Da Silva AGM, Rodrigues TS, et al. Furfural oxidation on gold supported on $\mathrm{MnO}_{2}$ : influence of the support structure on the catalytic performances. Appl Sci. 2018;8:1246. https://doi. org/10.3390/app8081246.

Genuino HC, Dharmarathna S, Njagi EC, et al. Gas-phase total oxidation of benzene, toluene, ethylbenzene, and xylenes using shapeselective manganese oxide and copper manganese oxide catalysts. J Phys Chem C. 2012;116(22):12066-78. https://doi.org/10.1021/ jp301342f.

Hoffmann B, Luttmann-Gibson H, Cohen A, et al. Opposing effects of particle pollution, ozone, and ambient temperature on arterial blood pressure. Environ Health Perspect. 2012;120(2):241-6. https://doi.org/10.1289/ehp.1103647.

Hou J, Luo J, Hu Z, et al. Tremendous effect of oxygen vacancy defects on the oxidation of arsenite to arsenate on cryptomelane-type manganese oxide. Chem Eng J. 2016;306:597-606. https://doi. org/10.1016/j.cej.2016.07.072.

Jia J, Zhang P, Chen L. Catalytic decomposition of gaseous ozone over manganese dioxides with different crystal structures. Appl Catal B Environ. 2016a;189:210-8. https://doi.org/10.1016/j.apcat b.2016.02.055.

Jia J, Zhang P, Chen L. The effect of morphology of $\alpha-\mathrm{MnO}_{2}$ on catalytic decomposition of gaseous ozone. Catal Sci Technol. 2016b;6(15):5841-7. https://doi.org/10.1039/C6CY00301J.

Jia J, Yang W, Zhang P, et al. Facile synthesis of Fe-modified manganese oxide with high content of oxygen vacancies for efficient airborne ozone destruction. Appl Catal A Gen. 2017;546:79-86. https://doi.org/10.1016/j.apcata.2017.08.013.

Li W, Gibbs GV, Oyama ST. Mechanism of ozone decomposition on a manganese oxide catalyst. 1. In situ Raman spectroscopy and ab initio molecular orbital calculations. J Am Chem Soc. 1998;120(35):9041-6. https://doi.org/10.1021/ja9814422.

Li J, Wang R, Hao J. Role of lattice oxygen and Lewis acid on ethanol oxidation over OMS-2 catalyst. J Phys Chem C. 2010;114(23):10544-50. https://doi.org/10.1021/jp102779u.

Lian Z, Ma J, He H. Decomposition of high-level ozone under high humidity over Mn-Fe catalyst: the influence of iron precursors. 
Catal Commun. 2015;59:156-60. https://doi.org/10.1016/j.catco m.2014.10.005.

Lin F, Wang Z, Ma Q, et al. Catalytic deep oxidation of NO by ozone over $\mathrm{MnO}_{x}$ loaded spherical alumina catalyst. Appl Catal B Environ. 2016;198:100-11. https://doi.org/10.1016/j.apcat b.2016.05.058.

Liu Y, Zhang P. Removing surface hydroxyl groups of Ce-modified $\mathrm{MnO}_{2}$ to significantly improve its stability for gaseous ozone decomposition. J Phys Chem C. 2017;121(42):23488-97. https ://doi.org/10.1021/acs.jpcc.7b07931.

Liu Y, Li X, Liu J, et al. Ozone catalytic oxidation of benzene over $\mathrm{AgMn} / \mathrm{HZSM}-5$ catalysts at room temperature: effects of Mn loading and water content. Chin J Catal. 2014;35(9):1465-74. https:// doi.org/10.1039/C3CY01102J.

Luo J, Zhang Q, Garcia-Martinez J, et al. Adsorptive and acidic properties, reversible lattice oxygen evolution, and catalytic mechanism of cryptomelane-type manganese oxides as oxidation catalysts. J Am Chem Soc. 2008;130(10):3198-207. https://doi.org/10.1021/ ja077706e.

Ma J, Wang C, He H. Transition metal doped cryptomelane-type manganese oxide catalysts for ozone decomposition. Appl Catal B Environ. 2017;201:503-10. https://doi.org/10.1016/j.apcat b.2016.08.050

Meng Y, Song W, Huang H, et al. Structure-property relationship of bifunctional $\mathrm{MnO}_{2}$ nanostructures: highly efficient, ultrastable electrochemical water oxidation and oxygen reduction reaction catalysts identified in alkaline media. J Am Chem Soc. 2014;136(32):11452-64. https://doi.org/10.1021/ja505186m.

Mitchell MB, Sheinker VN, Cox WW Jr, et al. Sustained room temperature decomposition of dimethyl methylphosphonate (DMMP) by $\mathrm{O}_{3}$ on alumina-supported $\mathrm{MnO}_{x}$. J Phys Chem C. 2011;115(23):11514-24. https://doi.org/10.1021/jp1091416.

Mohamed EF, Awad G, Zaitan H, et al. Transition metals-incorporated zeolites as environmental catalysts for indoor air ozone decomposition. Environ Technol. 2018;39(7):878-86. https://doi. org/10.1080/09593330.2017.1315457.

Naydenov A, Konova P, Nikolov P, et al. Decomposition of ozone on $\mathrm{Ag} / \mathrm{SiO}_{2}$ catalyst for abatement of waste gases emissions. Catal Today. 2008;137(2-4):471-4. https://doi.org/10.1016/j.catto d.2007.11.020.

Radhakrishnan R, Oyama ST. Ozone decomposition over manganese oxide supported on $\mathrm{ZrO}_{2}$ and $\mathrm{TiO}_{2}$ : a kinetic study using in situ laser Raman spectroscopy. J Catal. 2001;199(2):282-90. https:// doi.org/10.1006/jcat.2001.3167.
Saputra E, Muhammad S, Sun H, et al. Different crystallographic one-dimensional $\mathrm{MnO}_{2}$ nanomaterials and their superior performance in catalytic phenol degradation. Environ Sci Technol. 2013;47(11):5882-7. https://doi.org/10.1021/es400878c.

Seo SE, Choi SH. Preparation of the nanostructured radioisotope metallic oxide by neutron irradiation for use as radiotracers. Appl Sci. 2017;7(11):1115. https://doi.org/10.3390/app7111115.

Shindell D, Kuylenstierna JCI, Vignati E, et al. Simultaneously mitigating near-term climate change and improving human health and food security. Science. 2012;335(6065):183-9. https://doi. org/10.1126/science.1210026.

Stoyanova M, Konova P, Nikolov P, et al. Alumina-supported nickel oxide for ozone decomposition and catalytic ozonation of $\mathrm{CO}$ and VOCs. Chem Eng J. 2006;122(1-2):41-6. https://doi. org/10.1016/j.cej.2006.05.018.

Sun M, Yu L, Ye F, et al. Transition metal doped cryptomelane-type manganese oxide for low-temperature catalytic combustion of dimethyl ether. Chem Eng J. 2013;220:320-7. https://doi. org/10.1016/j.cej.2013.01.061.

Wang $\mathrm{C}$, Zhang $\mathrm{C}$, Zhao Y, et al. Poisoning effect of $\mathrm{SO}_{2}$ on honeycomb cordierite-based $\mathrm{Mn}-\mathrm{Ce} / \mathrm{Al}_{2} \mathrm{O}_{3}$ catalysts for $\mathrm{NO}$ reduction with $\mathrm{NH}_{3}$ at low temperature. Appl Sci. 2011;8(1):95. https://doi. org/10.3390/app8010095.

Wang C, Ma J, Liu F, et al. The effects of $\mathrm{Mn}^{2+}$ precursors on the structure and ozone decomposition activity of cryptomelanetype manganese oxide (OMS-2) catalysts. J Phys Chem C. 2015;119(40):23119-26. https://doi.org/10.1021/acs.jpcc.5b080 95.

Yang L, Hu C, Nie Y, et al. Catalytic ozonation of selected pharmaceuticals over mesoporous alumina-supported manganese oxide. Environ Sci Technol. 2009;43(7):2525-9. https://doi.org/10.1021/ es803253c.

Yu Q, Pan H, Zhao M, et al. Influence of calcination temperature on the performance of $\mathrm{Pd}-\mathrm{Mn} / \mathrm{SiO}_{2}-\mathrm{Al}_{2} \mathrm{O}_{3}$ catalysts for ozone decomposition. J Hazard Mater. 2009;172(2-3):631-4. https://doi. org/10.1016/j.jhazmat.2009.07.040.

Zhang P, Zhang B, Shi R. Catalytic decomposition of low level ozone with gold nanoparticles supported on activated carbon. Front Environ Sci Eng China. 2009;3(3):281-8. https://doi.org/10.1007/ s11783-009-0032-5.

Zhu G, Zhu J, Jiang W, et al. Surface oxygen vacancy induced $\alpha-\mathrm{MnO}_{2}$ nanofiber for highly efficient ozone elimination. Appl Catal B Environ. 2017;209:729-37. https://doi.org/10.1016/j.apcat b.2017.02.068. 